\title{
Genetic manipulation of lignocellulosic biomass for bioenergy
}

Peng Wang ${ }^{1}$, Natalia Dudareva ${ }^{1}$, John Morgan ${ }^{1,2}$, Clint Chapple ${ }^{1}$

${ }^{1}$ Department of Biochemistry, Purdue University, West Lafayette, IN 47907-2063

${ }^{2}$ School of Chemical Engineering, Purdue University, West Lafayette, IN 47907-2100

Corresponding author: Clint Chapple

Department of Biochemistry

Purdue University

175 S. University Street

West Lafayette, IN 47907-2063

Phone/ 765-494-0657

Fax/ 765-494-7897

Email/ chapple@purdue.edu 


\section{Abstract}

Lignocellulosic biomass represents an abundant and sustainable raw material for biofuel production. The recalcitrance of biomass to degradation increases the estimated cost of biofuel production and limits its competitiveness in the market. Genetic engineering of lignin, a major recalcitrance factor, improves saccharification and thus the potential yield of biofuels. Recently, our understanding of lignification and its regulation has been advanced by new studies in various systems, all of which further enhances our ability to manipulate the biosynthesis and deposition of lignin in energy crops for producing cost-effective second generation biofuels.

\section{Introduction}

Lignocellulose accounts for $70 \%$ of the carbon fixed by photosynthesis in land plants every year and a substantial amount of this biomass is available for use by humans [1]. Conversion of lignocellulosic feedstocks to biofuels has become increasingly attractive as a partial replacement for petroleum [2,3]. In contrast to bioethanol derived from starch, proposed lignocellulosic biofuel production facilities would use forest or crop residues and perennial grasses as feedstocks [1,2]. Biochemical and genetic investigations of lignocellulose in energy crops such as poplar, sorghum, sugarcane, miscanthus, and switchgrass are motivated by improving biofuel yield and providing a carbon-neutral source of transportation fuel.

Plant secondary cell walls are largely composed of cellulose, hemicelluloses and lignin. Cellulose, a $\beta-1,4$-linked polymer of glucose, is the most abundant component in secondary cell walls and hence the major source of sugar units used in biofuel production. Hemicelluloses include mannans, xylans, xyloglucans, or mixed-linkage glucans, which interact with cellulose to form a semi-rigid matrix [4]. Lignin is a heterogeneous polymer predominantly constituted of three subunits, namely $p$-hydroxyphenyl $(H)$, guaiacyl $(G)$, and syringyl $(S)$ monolignols. These monomers are derived from phenylalanine through the phenylpropanoid pathway, the structure of which is now well established (Figure 1) [5]. Lignin imparts mechanical strength and hydrophobicity to cell walls, but decreases saccharification efficiency and thereby increases the cost of lignocellulosic biofuel production. Fortunately, genetic modification of lignification results in changes in lignin content and/or composition, which in many cases leads to improved enzymatic digestion of the polysaccharide components of the cell wall [6-8]. Here, we summarize recent advances in the genetic manipulation of model plants and energy crops for enhanced fermentable sugar release.

\section{Identification of new genes for lignin manipulation}

Lignification is the consequence of coordinated monolignol biosynthesis and oxidative polymerization, both of which are tightly regulated transcriptionally and post-translationally [5,9]. The identification and functional characterization of the genes involved in these processes provide potential targets for modifying lignin and improving saccharification. For example, the recent discovery of caffeoyl shikimate esterase (CSE) revealed that this enzyme catalyzes the release of caffeate from caffeoyl shikimate which can then be utilized by 4-coumarate CoA ligase (4CL) to form caffeoyl CoA, an important intermediate for monolignol biosynthesis (Figure 1) [10]. In effect, the CSE/4CL route bypasses the transfer of the caffeoyl moiety from caffeoyl 
shikimate back to CoA by hydroxycinnamoyl CoA: shikimate hydroxycinnamoyl transferase (HCT). The cse mutant accumulates less total lignin but over 30 -fold more $\mathrm{H}$ units compared with wild-type Arabidopsis. Although the cse mutant produces less biomass, it releases $75 \%$ more glucose on a per plant basis during saccharification without pretreatment. As another example, cytochrome P450 reductases (CPRs) are also important for lignification because they transfer electrons from NADPH to the three cytochrome $\mathrm{P} 450$ hydroxylases required for monolignol synthesis, cinnamate 4-hydroxylase $(\mathrm{C} 4 \mathrm{H})$, p-coumarate 3'-hydroxylase $\left(\mathrm{C}^{\prime} \mathrm{H}\right)$, and ferulate 5-hydroxylase (F5H) [11]. Although it had been assumed that the CPRs in Arabidopsis were functionally redundant, it was recently demonstrated that the Arabidopsis atr2 mutant, defective in CPR2, produces less total lignin with a 10-fold enhancement in $\mathrm{H}$ unit content, and also exhibits improved glucose yields when alkaline-pretreated stems are saccharified [12].

Disruption of genes required for lignin polymerization also results in reduced lignin content and altered composition. Laccases (LACs) has been proposed to activate monolignols for radical coupling in the apoplast [5]. The first in vivo evidence came from the Arabidopsis lac4 lac17 double mutant, which displays an irregular xylem phenotype and has $40 \%$ less lignin with an increased S/G ratio. These phenotypes led to higher glucose release when the mutant's cell wall residue was hydrolyzed with commercial cellulase [13]. The Brachypodium lac5 mutant also deposits less lignin and exhibits enhanced saccharification, further demonstrating that $L A C s$ are potential genetic targets for improving biofuel production in monocot energy crops [14]. Like LACs, peroxidases have been shown to oxidize monolignols [5] and participate in lignin deposition in the Casparian strip [15], but more in planta data are necessary to define the biological functions of different peroxidases in vascular lignification [16,17]. Clearly, enzymes involved in both monomer synthesis and polymerization hold promise as tools for the improvement of biofuel crops.

The introduction of genes from other organisms is an alternative strategy to perturb lignin biosynthesis that is independent of the modification of endogenous plant genes. For example, the plastidial expression of 3-dehydroshikimate dehydratase from Corynebacterium glutamicum in Arabidopsis diverts flux from the shikimate pathway to synthesize protocatechuate, causes a $50 \%$ reduction in total lignin content and results in enhanced sugar release after enzymatic hydrolysis [18]. An interesting observation is that diverting carbon flux away from the shikimate pathway affects downstream lignification but not the pools of aromatic amino acids or salicylic acid [18]. These findings demonstrate that expression of foreign genes can also be used to redirect flux away from lignin and to reduce the recalcitrance of biomass for bioenergy production.

\section{Modification of lignin monomers}

In addition to the three primary $p$-hydroxycinnamyl alcohols, native lignins also contain numerous additional phenolic metabolites such as hydroxycinnamaldehydes, hydroxycinnamic acids, and hydroxybenzaldehydes [19]. When lignin biosynthesis is genetically perturbed, phenylpropanoid intermediates that accumulate as a result can be incorporated into the polymer (Figure 2) [5-7]. Indeed, overexpression of $\mathrm{F5H}$ in caffeic acid O-methyltransferase (COMT) deficient Arabidopsis mutant resulted in an increased deposition of 5-hydroxyguaiacyl units in 
lignin (Figure 1) [20,21]. Similarly, a catechyl lignin polymer derived from caffeyl alcohol was identified in CAFFEOYL COA O-METHYLTRANSFERASE (CCOAOMT) suppressed pine cell culture (Figure 1) like that recently characterized in the seed coat of a variety of members of the Orchidaceae, Cactaceae, Euphorbiaceae, and Cleomaceae [22-24]. The abundance of benzodioxane structures in these two novel lignin types can minimize potential cross-linking between lignin a-carbons and hemicellulosic alcohol or acid groups (Figure 3) [19]. This suggests that the engineering of plants that deposit catechyl lignin might lead to improved cellulose conversion, similar to the COMT-deficient switchgrass and alfalfa that have been developed recently that deposit lignin with increased 5-hydroxyconiferyl alcohol monomer content [25-27].

The plasticity of lignin biosynthesis and polymerization makes it possible to incorporate new monomers and thus new functionality into the lignin polymer or to interfere with polymerization. An array of phenolic compounds has been proposed as promising candidates to improve saccharification through these mechanisms [19]. The first example successfully realized in vivo involved heterologous expression of an Angelica sinensis feruloyl CoA monolignol transferase in poplar, which resulted in the incorporation of ferulate conjugates into the lignin backbone (Figure 3) [28]. The novel lignins formed did not impact the growth of the poplar trees but the ester bonds within these novel lignin building blocks could be easily cleaved by alkaline pretreatment post-harvest, thus enhancing the release of sugar [28]. Instead of "editing" monolignols before polymerization, enzymatic modification of the lignin polymer itself can also result in readily cleavable bonds. A C- $\alpha$ dehydrogenase from Sphingobium was shown to oxidize the hydroxyl group of the $\alpha$-carbon in $\beta$-O-4 linked dilignols and oligolignols in vitro or when expressed in Arabidopsis (Figure 3) [29]. Lignin of the transgenic lines showed only a small increase in $\alpha$-keto $\beta-\mathrm{O}-4$ linkages presumably because most of the $\mathrm{C}-\alpha$ dehydrogenase appeared to localize to the cytoplasm even though it had been targeted for secretion [29]. It might be possible to attain higher levels of $\alpha$-keto $\beta-O-4$ linkages in lignin in the future if the $C-\alpha$ dehydrogenase can be successfully targeted to the apoplast of lignifying cells.

The elongation of the lignin polymer is mainly the result of $\beta$-O-4 coupling between the $\beta$-carbon of monomers and the $4-O$ position of oligomers $[7,19]$. Monomers that lack a $\beta$-carbon or in which the para-hydroxyl group is blocked prevent the polymer from growing. For example, hydroxybenzaldehydes are known as minor non-conventional monomers in a variety of species and form end groups in natural lignins (Figure 3) [30]. To increase these end units and alter lignin architecture, a Pseudomonas fluorescens hydroxycinnamoyl CoA hydratase-lyase was expressed in Arabidopsis [31]. Although the transgenics displayed normal growth, they contained more reduced-length lignins and provided an increased yield of sugars after various pretreatments [31]. Methylation of the para-hydroxyl group of monolignols is another way to reduce polymerization by preventing $\beta$-O- 4 linkages with the free monomers. The Clarkia breweri isoeugenol $O$-methyltransferase was engineered to catalyze the 4-O-methylation of monolignols, and expression of this enzyme in Arabidopsis reduced lignin content and led to elevated glucose yield without pretreatment [32]. Taken together, these results show that genetic manipulation of lignification can result in the incorporation of non-conventional monomers with positive impacts on biomass utility. 


\section{Regulation of lignocellulose biosynthesis}

A hierarchical transcriptional network regulates secondary cell wall biosynthesis in plants, and coordinates cell elongation, differentiation, synthesis of polysaccharides and lignin, and programmed cell death [9]. The top-level master switches include a series of tissue-specific NAM, ATAF1,2, and CUC2 (NAC) transcription factors, which activate the secondary-level MYB master switches, such as MYB46 and MYB83 in Arabidopsis. These master switches together turn on downstream transcription factors and directly regulate the biosynthetic genes of the secondary cell wall $[9,33]$. Feed-forward loops between different transcription factors make the network robust in regulating secondary cell wall synthesis. To describe this network, TaylorTeeples et al. utilized DNA-protein binding assays to study the complex regulatory feed-forward cascades controlling Arabidopsis lignocellulosic biosynthesis [34]. In terms of feedstock genetic engineering, one advantage of transcription factor manipulation is that multiple genes can be simultaneously regulated to restrict or enhance flux towards lignocellulose. Such an approach avoids the necessity of stacking of biosynthetic genes (or their mutants) to achieve desired phenotypes. For example, overexpression of MYB4 in switchgrass, a transcriptional repressor of lignification, reduces the transcription of 10 lignin biosynthetic genes, decreases lignin content and increases cellulosic ethanol yield up to 2.6 fold $[35,36]$.

It was recently demonstrated that transcriptional regulation of phenylpropanoid metabolism in plants is also dependent on the Mediator complex. Subunits of Mediator, MED5a and MED5b, suppress the steady state level of phenylpropanoid biosynthetic mRNAs in Arabidopsis [37]. Knocking-out MED5a and MED5b enhances phenylpropanoid gene expression and end product accumulation. Surprisingly, it also substantially alleviates the mis-regulation of transcription in the stunted and lignin-deficient Arabidopsis c3' $h$ mutant, in which one-third of the transcriptome is differentially expressed, rescues its arrested growth and restores lignin deposition to wild-type levels (Figure 4) [38,39]. Most importantly, due to the defect in $\mathrm{C}^{\prime} \mathrm{H}$, the mutant's lignin is almost exclusively derived from $\mathrm{H}$ subunits, demonstrating that these monomers can be polymerized into a functional lignin that supports normal growth. The deposition of this novel lignin doubles the saccharification efficiency of the mutant's biomass compared to the wild-type [38].

In addition to regulation at the transcriptional level, posttranslational regulation also controls lignin biosynthesis [40]. It has recently been shown that ubiquitination and degradation of phenylalanine ammonia lyase (PAL), the first enzyme in the phenylpropanoid pathway, is mediated by Kelch-repeat-containing F box (KFB) proteins, components of the SCF type E3 ligase [41,42]. Overexpression of the KFBs facilitates the proteolysis of PAL and results in a reduction in lignin content and soluble phenylpropanoids in Arabidopsis [41,42] and may provide a novel approach to biomass modification in the future.

\section{Engineering of energy crops for lignocellulosic utilization}

An increasing number of studies conducted directly on energy crops have identified promising strains for biofuel production, including spontaneous or chemically-induced mutants. Mutant screens are particularly facile when visible markers are available. Brown midrib mutations, first found in natural maize mutants, are clearly visible to the unaided eye, and are associated with 
reduced lignin content or altered lignin composition [43]. Random mutagenesis screens of sorghum were conducted to identify brown midrib (bmr) mutants and so far three independent loci have been isolated and found to encode 4CL (bmr2), CAD (bmr6), COMT (bmr12), respectively [43-45]. Characterization of these mutants showed a $7-20 \%$ increase in saccharification efficiency and a further $20 \%$ increase when $b m r 6$ and $b m r 12$ mutations are stacked $[45,46]$.

Translation of genetic engineering strategies established in model plants into energy crops requires a comprehensive knowledge of lignification in these target species. Advanced sequencing technologies have enabled the systematic identification of lignin biosynthetic candidate genes in poplar (Populus trichocarpa), Eucalyptus grandis, switchgrass (Panicum virgatum), and sugarcane (Saccharum spp.) thus facilitating reverse genetic analysis in these crops [47-50]. For example, RNAi mediated down-regulation of $C^{\prime} 3^{\prime} H$ in poplar resulted in lower lignin content and higher glucose release by enzymatic hydrolysis (Figure 2) [51,52] and the CRISPR/Cas9 system was successfully employed to mutate $4 C L 1$ and $4 C L 2$ in hybrid poplar [53].

To be economically viable for biofuel production, modified crops will need to thrive in the field and yield high amounts of biomass. A five-year field trial study showed a significant increase in enzymatic hydrolysis of cellulose in transgenic poplar deficient in CCOAOMT but no impacts on its growth or biomass [54]. Similarly, field-grown COMT-downregulated or MYB4 overexpressing switchgrass yielded increased amounts of fermentable sugars and comparable amounts of dry biomass $[55,56]$. Importantly, in the field these transgenic plants displayed no differences in disease susceptibility compared to wild-type controls. Elevated saccharification of lignocellulose was also observed in COMT-suppressed sugarcane and CCR downregulated poplar in field trials, but the improvements were accompanied by a reduction in biomass $[57,58]$. Although the higher cellulose conversion in the transgenic sugarcane and poplar compensates for the reduced biomass, the overall yield penalty in these lines remains an obstacle to be overcome before industrial utilization.

\section{Conclusions}

The production of cost-effective biofuels from abundant and renewable lignocellulosic feedstocks is impeded by the inherent recalcitrance of the biomass. Various genetic manipulations of lignification have demonstrated the power to reduce this stumbling block and increase the yield of fermentable sugars from engineered biomass. Alteration of lignin content and composition can be achieved by modification of endogenous plant genes or expression of heterologous genes. The introduction of novel monomers and increased levels of nonconventional subunits result in lignin with new functional groups and ease the removal of lignin for saccharification. Further, regulation of lignification at both transcriptional and posttranslational levels is shown to be effective targets to engineer lignin. Extension of the established strategies from model systems into energy crops and assessment of the mutants in the field are necessary for successful industrial application. Future studies must focus on overcoming the yield loss that often accompanies lignin modification. 


\section{Figures}

Figure 1. A simplified pathway illustrating the enzymes and metabolites involved in lignin biosynthesis. PAL, phenylalanine ammonia lyase; $\mathrm{C} 4 \mathrm{H}$, cinnamate 4-hydroxylase; 4CL, 4coumarate CoA ligase; HCT, hydroxycinnamoyl CoA:shikimate hydroxycinnamoyl transferase; C3'H, p-coumaroyl shikimate 3'-hydroxylase; CSE, caffeoyl shikimate esterase; CCoAOMT, caffeoyl CoA O-methyltransferase; $\mathrm{F} 5 \mathrm{H}$, ferulate 5-hydroxylase; COMT, caffeic acid $\mathrm{O}$ methyltransferase; CCR, cinnamoyl CoA reductase; CAD, cinnamyl alcohol dehydrogenase; LAC, laccase; PRX, peroxidase. Structures of the five hydroxycinnamyl alcohols are included. Reactions in grey indicate that these steps are of only minor importance in wild-type plants.

Figure 2. A simplified model illustrating that manipulations of lignin biosynthetic genes change pathway flux. In flowering plants, the pathway generates $\mathrm{H}, \mathrm{G}$, and $\mathrm{S}$ lignin. When $\mathrm{C}^{\prime} \mathrm{H}$ is perturbed (blue $X$ ), the flux towards $G$ and $S$ is blocked and mutants deposit $H$ lignin (blue line). When $F 5 H$ is silenced (red $X$ ), the $S$ branch is blocked and mutants contain almost exclusively $\mathrm{G}$ lignin (red line). When $\mathrm{F} 5 \mathrm{H}$ is overexpressed (green check), the $\mathrm{G}$ flux is redirected towards $\mathrm{S}$ monomers so transgenics accumulate predominantly $S$ lignin (green line).

Figure 3. A model of lignin polymer illustrates the native and modified monomers and structural units. The major monomers are coniferyl alcohols $\left(R=O M e, R^{\prime}=H\right)$ and sinapyl alcohols $\left(R=R^{\prime}=\mathrm{OMe}\right)$, and the major structural units are $\beta$-ether units (black) in wild-type plants. Wildtype lignin also includes phenylcoumaran units (green), resinol units (purple), and biphenyl ether units (blue). Cinnamyl alcohols $\left(\mathrm{R}=\mathrm{OMe}, \mathrm{R}^{\prime}=\mathrm{OMe}\right.$ or $\left.\mathrm{H}\right)$ (pink) and hydroxybenzaldehydes $\left(\mathrm{R}=\mathrm{OMe}, \mathrm{R}^{\prime}=\mathrm{OMe}\right.$ or $\mathrm{H}$ ) (cyan) are often seen as end groups. Incorporation of caffeyl alcohol $(\mathrm{R}=\mathrm{H})$ or 5-hydroxyconiferyl alcohol $(\mathrm{R}=\mathrm{OMe})$ results in benzodioxane units (brown) in the lignin polymers. Incorporation of monolignol ferulate (red) introduces the ester bond into the lignin backbone, forming ZipLignin ${ }^{\mathrm{TM}}$. Oxidation of hydroxyl group on the $\alpha$-carbon results in $\alpha$-keto $\beta$ O-4 linkages (orange).

Figure 4. Knocking-out MED5a and MED5b substantially rescues the arrested growth of Arabidopsis ref8-2 mutant that contains a T-DNA insertion in the gene encoding $\mathrm{C}^{\prime} \mathrm{H}$. Wild-type, med5a/5b, ref8-2, and med5a/5b ref8-2 plants were photographed four weeks after planting. The ref8- 2 mutant is dwarf and sterile, but the triple mutant med5a/5b ref8-2 has restored growth and is fertile. Photograph provided by Nicholas D. Bonawitz.

\section{Acknowledgements}

The preparation of this manuscript was supported by the U.S. Department of Energy, Office of Science, Office of Biological and Environmental Research, Genomic Science program, under Award Number DE-SC0008628. 


\section{References and recommended reading}

Papers of particular interest, published within the period of review, have been highlighted as:

- of special interest

•• of outstanding interest

1. Pauly M, Keegstra K: Cell-wall carbohydrates and their modification as a resource for biofuels. Plant $J$ 2008, 54:559-568.

2. Somerville C: Next generation biofuels. AIP Conference Proceedings 2015, 1652:44-50.

3. Limayem A, Ricke SC: Lignocellulosic biomass for bioethanol production: current perspectives, potential issues and future prospects. Prog Energy Combust Sci 2012, 38:449-467.

4. Pauly M, Gille S, Liu LF, Mansoori N, de Souza A, Schultink A, Xiong GY: Hemicellulose biosynthesis. Planta 2013, 238:627-642.

5. Bonawitz ND, Chapple C: The genetics of lignin biosynthesis: connecting genotype to phenotype. Annu Rev Genet 2010, 44:337-363.

6. Liu CJ, Cai Y, Zhang Y, Gou M, CJ, Cai Y, Zhang X, Gou M, Yang H. Tailoring lignin biosynthesis for efficient and sustainable biofuel production. Plant Biotechnol $J$ 2014, 12:1154-1162.

-7. Van Acker R, Vanholme R, Storme V, Mortimer JC, Dupree P, Boerjan W: Lignin biosynthesis perturbations affect secondary cell wall composition and saccharification yield in Arabidopsis thaliana. Biotechnol Biofuels 2013, 6. describes comprehensively the effect of perturbation at each lignin biosynthetic step on secondary cell wall composition and saccharification efficiency.

8. Li X, Ximenes E, Kim Y, Slininger M, Meilan R, Ladisch M, Chapple C: Lignin monomer composition affects Arabidopsis cell-wall degradability after liquid hot water pretreatment. Biotechnol Biofuels 2010, 3:27.

9. Zhong R, Ye ZH: Secondary cell walls: biosynthesis, patterned deposition and transcriptional regulation. Plant Cell Physiol 2015, 56:195-214.

••10. Vanholme R, Cesarino I, Rataj K, Xiao Y, Sundin L, Goeminne G, Kim H, Cross J, Morreel $K$, Araujo $P$, et al.: Caffeoyl shikimate esterase (CSE) is an enzyme in the lignin biosynthetic pathway in Arabidopsis. Science 2013, 341:1103-1106.

reports the identification of a new enzyme involved in the phenylpropanoid metabolism and causes a revision of the pathway.

11. Urban P, Mignotte C, Kazmaier M, Delorme F, Pompon D: Cloning, yeast expression, and characterization of the coupling of two distantly related Arabidopsis thaliana NADPH-cytochrome P450 reductases with P450 CYP73A5. J Biol Chem 1997, 272:19176-19186.

12. Sundin L, Vanholme R, Geerinck J, Goeminne G, Hofer R, Kim H, Ralph J, Boerjan W: Mutation of the inducible ARABIDOPSIS THALIANA CYTOCHROME P450 REDUCTASE2 alters lignin composition and improves saccharification. Plant Physiol 2014, 166:1956-1971.

13. Berthet S, Demont-Caulet N, Pollet B, Bidzinski P, Cezard L, Le Bris P, Borrega N, Herve J, Blondet $\mathrm{E}$, Balzergue $\mathrm{S}$, et al.: Disruption of LACCASE4 and 17 results in tissuespecific alterations to lignification of Arabidopsis thaliana stems. Plant Cell 2011, 23:1124-1137.

14. Wang Y, Bouchabke-Coussa O, Le Bris P, Antelme S, Soulhat C, Gineau E, Dalmais M, Bendahmane A, Morin H, Mouille $\mathrm{G}$, et al.: LACCASE5 is required for lignification of the Brachypodium distachyon culm. Plant Physiol 2015. 
15. Lee Y, Rubio MC, Alassimone J, Geldner N: A mechanism for localized lignin deposition in the endodermis. Cell 2013, 153:402-412.

16. Francoz E, Ranocha P, Nguyen-Kim H, Jamet E, Burlat V, Dunand C: Roles of cell wall peroxidases in plant development. Phytochem 2015, 112:15-21.

17. Herrero J, Esteban-Carrasco A, Zapata JM: Looking for Arabidopsis thaliana peroxidases involved in lignin biosynthesis. Plant Physiol Biochem 2013, 67:77-86.

-18. Eudes A, Sathitsuksanoh N, Baidoo EE, George A, Liang Y, Yang F, Singh S, Keasling JD, Simmons BA, Loque D: Expression of a bacterial 3-dehydroshikimate dehydratase reduces lignin content and improves biomass saccharification efficiency. Plant Biotechnol J 2015. reports that the manipulation of the shikimate pathway diverts the flux away from lignin and leads to increased enzymatic digestibility of lignocellulose.

-19. Vanholme R, Morreel K, Darrah C, Oyarce P, Grabber JH, Ralph J, Boerjan W: Metabolic engineering of novel lignin in biomass crops. New Phytol 2012, 196:978-1000. describes in-depth a library of candidate phenolic compounds as lignin monomers for improvement in lignocellulosic biofuel production.

20. Weng JK, Mo H, Chapple C: Over-expression of F5H in COMT-deficient Arabidopsis leads to enrichment of an unusual lignin and disruption of pollen wall formation. Plant J 2010, 64:898-911.

21. Vanholme R, Ralph J, Akiyama T, Lu F, Pazo JR, Kim H, Christensen JH, Van Reusel B, Storme V, De Rycke R, et al.: Engineering traditional monolignols out of lignin by concomitant up-regulation of F5H1 and down-regulation of COMT in Arabidopsis. Plant J 2010, 64:885-897.

-22. Chen F, Tobimatsu Y, Havkin-Frenkel D, Dixon RA, Ralph J: A polymer of caffeyl alcohol in plant seeds. Proc Natl Acad Sci USA 2012, 109:1772-1777. reports the first observation of natural catechyl lignin in plant seeds.

23. Tobimatsu Y, Chen F, Nakashima J, Escamilla-Trevino LL, Jackson L, Dixon RA, Ralph J: Coexistence but independent biosynthesis of catechyl and guaiacyl/syringyl lignin polymers in seed coats. Plant Cell 2013, 25:2587-2600.

24. Wagner A, Tobimatsu Y, Phillips L, Flint H, Torr K, Donaldson L, Pears L, Ralph J: CCOAOMT suppression modifies lignin composition in Pinus radiata. Plant $\mathrm{J} 2011$, 67:119-129.

25. Fu C, Mielenz JR, Xiao X, Ge Y, Hamilton CY, Rodriguez M, Jr., Chen F, Foston M, Ragauskas A, Bouton J, et al.: Genetic manipulation of lignin reduces recalcitrance and improves ethanol production from switchgrass. Proc Natl Acad Sci USA 2011, 108:3803-3808.

26. Dien BS, Miller DJ, Hector RE, Dixon RA, Chen F, McCaslin M, Reisen P, Sarath G, Cotta $M A$ : Enhancing alfalfa conversion efficiencies for sugar recovery and ethanol production by altering lignin composition. Bioresour Technol 2011, 102:6479-6486.

27. Sattler SE, Palmer NA, Saballos A, Greene AM, Xin ZG, Sarath G, Vermerris W, Pedersen JF: Identification and characterization of four missense mutations in brown midrib 12 (Bmr12), the caffeic O-methyltranferase (COMT) of sorghum. BioEnergy Res 2012, 5:855-865.

••28. Wilkerson CG, Mansfield SD, Lu F, Withers S, Park JY, Karlen SD, Gonzales-Vigil E, Padmakshan D, Unda F, Rencoret J, et al.: Monolignol ferulate transferase introduces chemically labile linkages into the lignin backbone. Science 2014 , 344:90-93.

demonstrates that monolignol ferulate can be synthesized and incorporated into lignin polymer and result in readily cleavable ester bonds in transgenic poplars expressing a monolignol ferulate transferase. 
29. Tsuji Y, Vanholme R, Tobimatsu Y, Ishikawa Y, Foster CE, Kamimura N, Hishiyama S, Hashimoto S, Shino A, Hara $\mathrm{H}$, et al.: Introduction of chemically labile substructures into Arabidopsis lignin through the use of LigD, the Ca-dehydrogenase from Sphingobium sp. strain SYK-6. Plant Biotechnol J 2015.

30. Kim H, Ralph J, Lu FC, Ralph SA, Boudet AM, MacKay JJ, Sederoff RR, Ito T, Kawai S, Ohashi $\mathrm{H}$, et al.: NMR analysis of lignins in CAD-deficient plants. Part 1. Incorporation of hydroxycinnamaldehydes and hydroxybenzaldehydes into lignins. Org Biomol Chem 2003, 1:268-281.

31. Eudes A, George A, Mukerjee P, Kim JS, Pollet B, Benke PI, Yang F, Mitra P, Sun L, Cetinkol OP, et al.: Biosynthesis and incorporation of side-chain-truncated lignin monomers to reduce lignin polymerization and enhance saccharification. Plant Biotechnol J 2012, 10:609-620.

32. Zhang K, Bhuiya MW, Pazo JR, Miao Y, Kim H, Ralph J, Liu CJ: An engineered monolignol 4-O-methyltransferase depresses lignin biosynthesis and confers novel metabolic capability in Arabidopsis. Plant Cell 2012, 24:3135-3152.

33. Zhong $R Q$, McCarthy $R L$, Lee $C$, Ye $Z H$ : Dissection of the transcriptional program regulating secondary wall biosynthesis during wood formation in poplar. Plant Physiol 2011, 157:1452-1468.

-34. Taylor-Teeples M, Lin L, de Lucas M, Turco G, Toal TW, Gaudinier A, Young NF, Trabucco GM, Veling MT, Lamothe R, et al.: An Arabidopsis gene regulatory network for secondary cell wall synthesis. Nature 2015, 517:571-U307. reports a comprehensive protein-DNA regulatory network for lignocellulose deposition in Arabidopsis root and stem, supporting the feed-forward loops for robust regulation of secondary cell wall synthesis.

35. Shen H, Poovaiah CR, Ziebell A, Tschaplinski TJ, Pattathil S, Gjersing E, Engle NL, Katahira R, Pu Y, Sykes R, et al.: Enhanced characteristics of genetically modified switchgrass (Panicum virgatum L.) for high biofuel production. Biotechnol Biofuels 2013, 6:71.

36. Shen H, He XZ, Poovaiah CR, Wuddineh WA, Ma JY, Mann DGJ, Wang HZ, Jackson L, Tang $\mathrm{YH}$, Stewart $\mathrm{CN}$, et al.: Functional characterization of the switchgrass (Panicum virgatum) R2R3-MYB transcription factor PvMYB4 for improvement of lignocellulosic feedstocks. New Phytol 2012, 193:121-136.

37. Bonawitz ND, Soltau WL, Blatchley MR, Powers BL, Hurlock AK, Seals LA, Weng JK, Stout J, Chapple C: REF4 and RFR1, subunits of the transcriptional coregulatory complex mediator, are required for phenylpropanoid homeostasis in Arabidopsis. J Biol Chem 2012, 287:5434-5445.

••38. Bonawitz ND, Kim JI, Tobimatsu Y, Ciesielski PN, Anderson NA, Ximenes E, Maeda J, Ralph J, Donohoe BS, Ladisch M, Chapple C: Disruption of Mediator rescues the stunted growth of a lignin-deficient Arabidopsis mutant. Nature 2014, 509:376-380. reports that Mediator is required for the dwarfism and lignin-deficiency in Arabidopsis ref8 mutants, and that $\mathrm{H}$ lignin can support the normal growth of plants and reduce the recalcitrance of lignocellulosic biomass.

39. Franke R, Hemm MR, Denault JW, Ruegger MO, Humphreys JM, Chapple C: Changes in secondary metabolism and deposition of an unusual lignin in the ref8 mutant of Arabidopsis. Plant J 2002, 30:47-59.

40. Zhang XB, Liu CJ: Multifaceted regulations of gateway enzyme phenylalanine ammonia-lyase in the biosynthesis of phenylpropanoids. Mol Plant 2015, 8:17-27.

-41. Zhang X, Gou M, Liu CJ: Arabidopsis Kelch repeat F-box proteins regulate phenylpropanoid biosynthesis via controlling the turnover of phenylalanine ammonia-lyase. Plant Cell 2013, 25:4994-5010. 
reports that KFB proteins mediate the degradation of PAL and regulate phenylpropanoid metabolism at the post-translational level.

42. Zhang XB, Gou MY, Guo CR, Yang HJ, Liu CJ: Down-regulation of Kelch domaincontaining F-box protein in Arabidopsis enhances the production of (poly)phenols and tolerance to ultraviolet radiation. Plant Physiol 2015, 167:337-U548.

43. Sattler SE, Funnell-Harris DL, Pedersen JF: Brown midrib mutations and their importance to the utilization of maize, sorghum, and pearl millet lignocellulosic tissues. Plant Science 2010, 178:229-238.

44. Xin Z, Wang ML, Barkley NA, Burow G, Franks C, Pederson G, Burke J. Applying genotyping (TILLING) and phenotyping analyses to elucidate gene function in a chemically induced sorghum mutant population. BMC Plant Biol 2008, 8:103.

45. Saballos A, Vermerris W, Rivera L, Ejeta G: Allelic association, chemical characterization and saccharification properties of brown midrib mutants of sorghum (Sorghum bicolor (L.) Moench). BioEnergy Res 2008, 1:193-204.

46. Dien BS, Sarath G, Pedersen JF, Sattler SE, Chen H, Funnell-Harris DL, Nichols NN, Cotta MA: Improved sugar conversion and ethanol yield for forage sorghum (Sorghum bicolor L. Moench) lines with reduced lignin contents. BioEnergy Res 2009, 2:153164.

47. Carocha V, Soler M, Hefer C, Cassan-Wang H, Fevereiro P, Myburg AA, Paiva JA, GrimaPettenati J: Genome-wide analysis of the lignin toolbox of Eucalyptus grandis. New Phytol 2015.

48. Bottcher A, Cesarino I, dos Santos AB, Vicentini R, Mayer JLS, Vanholme R, Morreel K, Goeminne G, Moura JCMS, Nobile PM, et al.: Lignification in sugarcane: biochemical characterization, gene discovery, and expression analysis in two genotypes contrasting for lignin content. Plant Physiol 2013, 163:1539-1557.

49. Shen H, Mazarei M, Hisano H, Escamilla-Trevino L, Fu C, Pu Y, Rudis MR, Tang Y, Xiao X, Jackson $L$, et al.: A genomics approach to deciphering lignin biosynthesis in switchgrass. Plant Cell 2013, 25:4342-4361.

50. Shi R, Sun YH, Li Q, Heber S, Sederoff R, Chiang VL: Towards a systems approach for lignin biosynthesis in Populus trichocarpa: transcript abundance and specificity of the monolignol biosynthetic genes. Plant Cell Physiol 2010, 51:144-163.

51. Mansfield SD, Kang KY, Chapple C: Designed for deconstruction - poplar trees altered in cell wall lignification improve the efficacy of bioethanol production. New Phytol 2012, 194:91-101.

52. Coleman HD, Park JY, Nair R, Chapple C, Mansfield SD: RNAi-mediated suppression of p-coumaroyl-CoA 3'-hydroxylase in hybrid poplar impacts lignin deposition and soluble secondary metabolism. Proc Natl Acad Sci USA 2008, 105:4501-4506.

•53. Zhou X, Jacobs TB, Xue LJ, Harding SA, Tsai CJ: Exploiting SNPs for biallelic CRISPR mutations in the outcrossing woody perennial Populus reveals 4-coumarate:CoA ligase specificity and redundancy. New Phytol 2015.

reports the first utilization of CRISPR/Cas9 system to manipulate lignin biosynthetic genes in plants.

54. Wang HZ, Xue YX, Chen YJ, Li RF, Wei JH: Lignin modification improves the biofuel production potential in transgenic Populus tomentosa. Ind Crops Prod 2012, 37:170-177.

55. Baxter HL, Mazarei M, Labbe N, Kline LM, Cheng QK, Windham MT, Mann DGJ, Fu CX, Ziebell A, Sykes RW, et al.: Two-year field analysis of reduced recalcitrance transgenic switchgrass. Plant Biotechnol J 2014, 12:914-924.

56. Baxter HL, Poovaiah C, Yee K, Mazarei M, Rodriguez M, Jr., Thompson O, Shen H, Turner $\mathrm{G}$, Decker S, Sykes R, et al.: Field evaluation of transgenic switchgrass plants 
overexpressing PvMYB4 for reduced biomass recalcitrance. BioEnergy Res 2015:112.

57. Van Acker R, Leple JC, Aerts D, Storme V, Goeminne G, Ivens B, Legee F, Lapierre C, Piens K, Van Montagu MCE, et al.: Improved saccharification and ethanol yield from field-grown transgenic poplar deficient in cinnamoyl-CoA reductase. Proc Natl Acad Sci USA 2014, 111:845-850.

58. Jung JH, Vermerris W, Gallo M, Fedenko JR, Erickson JE, Altpeter F: RNA interference suppression of lignin biosynthesis increases fermentable sugar yields for biofuel production from field-grown sugarcane. Plant Biotechnol J 2013, 11:709-716. 
phenylalanine

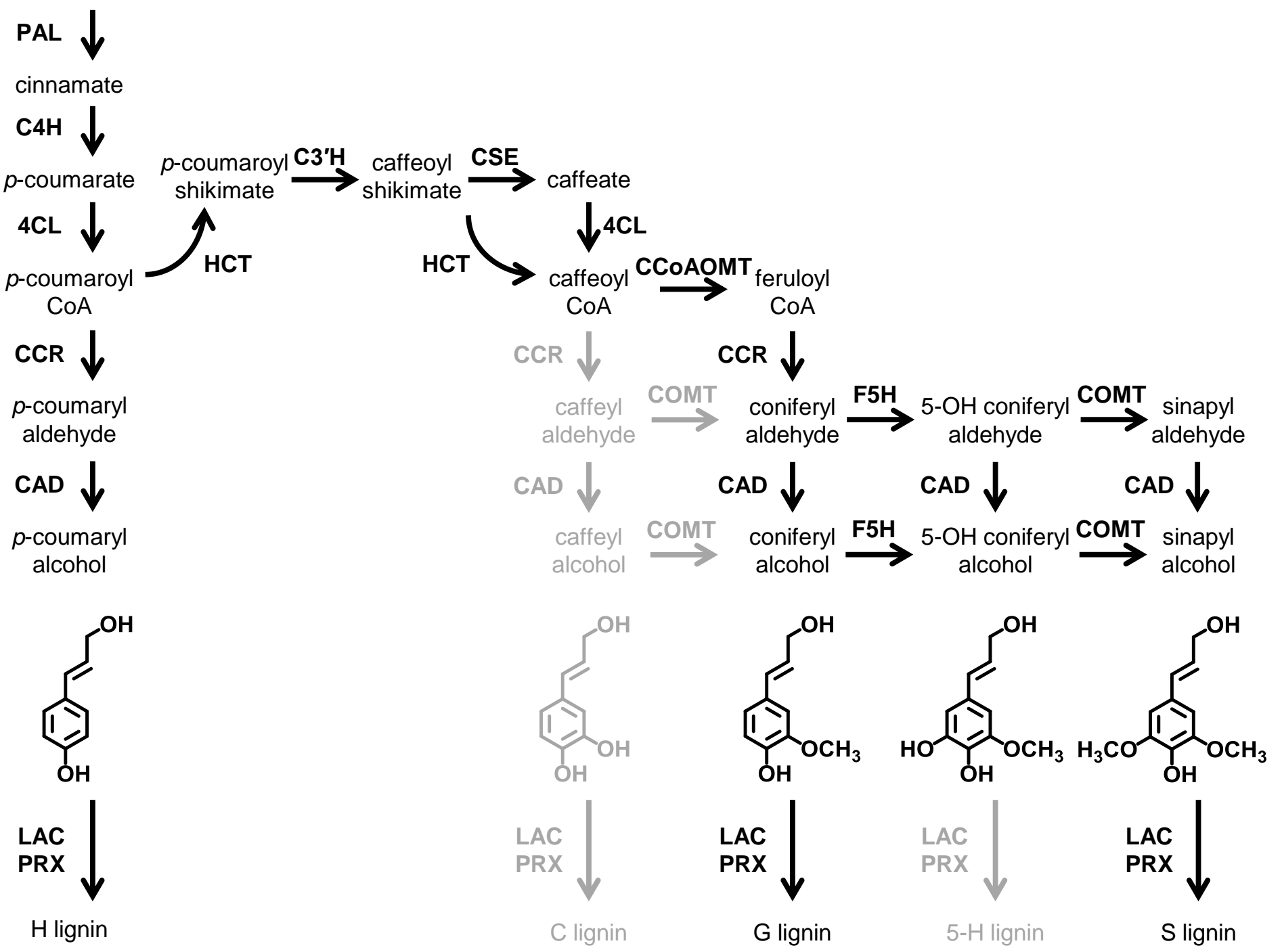

Figure 1. A simplified pathway illustrating the enzymes and metabolites involved in lignin biosynthesis. PAL, phenylalanine ammonia lyase; $\mathrm{C} 4 \mathrm{H}$, cinnamate 4-hydroxylase; $4 \mathrm{CL}$, 4-coumarate CoA ligase; $\mathrm{HCT}$, hydroxycinnamoyl CoA:shikimate hydroxycinnamoyl transferase; C3' $\mathrm{H}, p$-coumaroyl shikimate 3'-hydroxylase; CSE, caffeoyl shikimate esterase; CCoAOMT, caffeoyl CoA O-methyltransferase; F5H, ferulate 5hydroxylase; COMT, caffeic acid O-methyltransferase; CCR, cinnamoyl CoA reductase; CAD, cinnamyl alcohol dehydrogenase; LAC, laccase; PRX, peroxidase. Structures of the five hydroxycinnamyl alcohols are included. Reactions in grey indicate that these steps are of only minor importance in wild-type plants. 


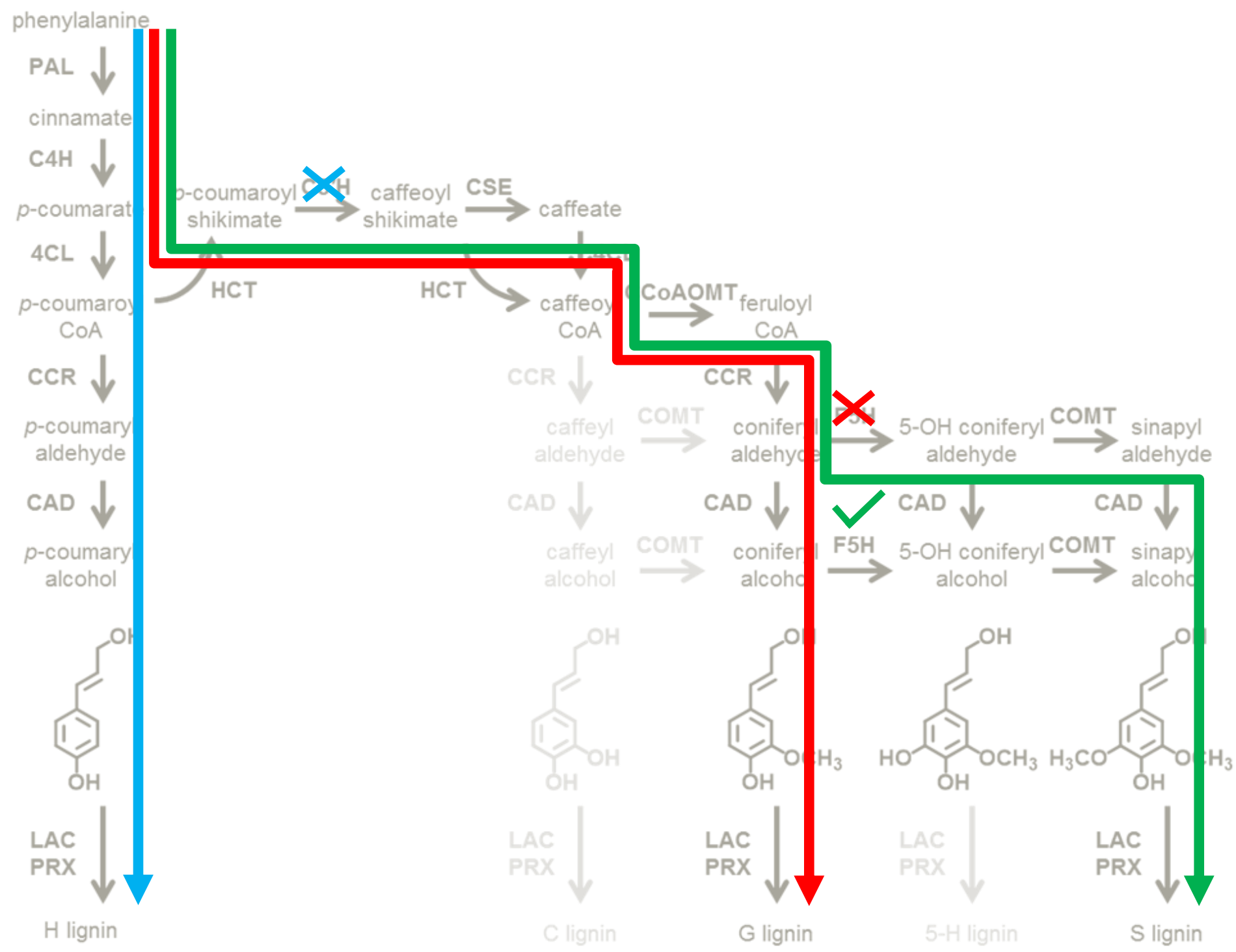

Figure 2. A simplified model illustrating that manipulations of lignin biosynthetic genes change pathway flux. In flowering plants, the pathway generates $\mathrm{H}, \mathrm{G}$, and $\mathrm{S}$ lignin. When $\mathrm{C} 3^{\prime} H$ is perturbed (blue $\mathrm{X}$ ), the flux towards $\mathrm{G}$ and $\mathrm{S}$ is blocked and mutants deposit $\mathrm{H}$ lignin (blue line). When $F 5 H$ is silenced (red $X$ ), the $S$ branch is blocked and mutants contain almost exclusively G lignin (red line). When $F 5 H$ is overexpressed (green check), the $\mathrm{G}$ flux is redirected towards $\mathrm{S}$ monomers so transgenics accumulate predominantly $\mathrm{S}$ lignin (green line). 


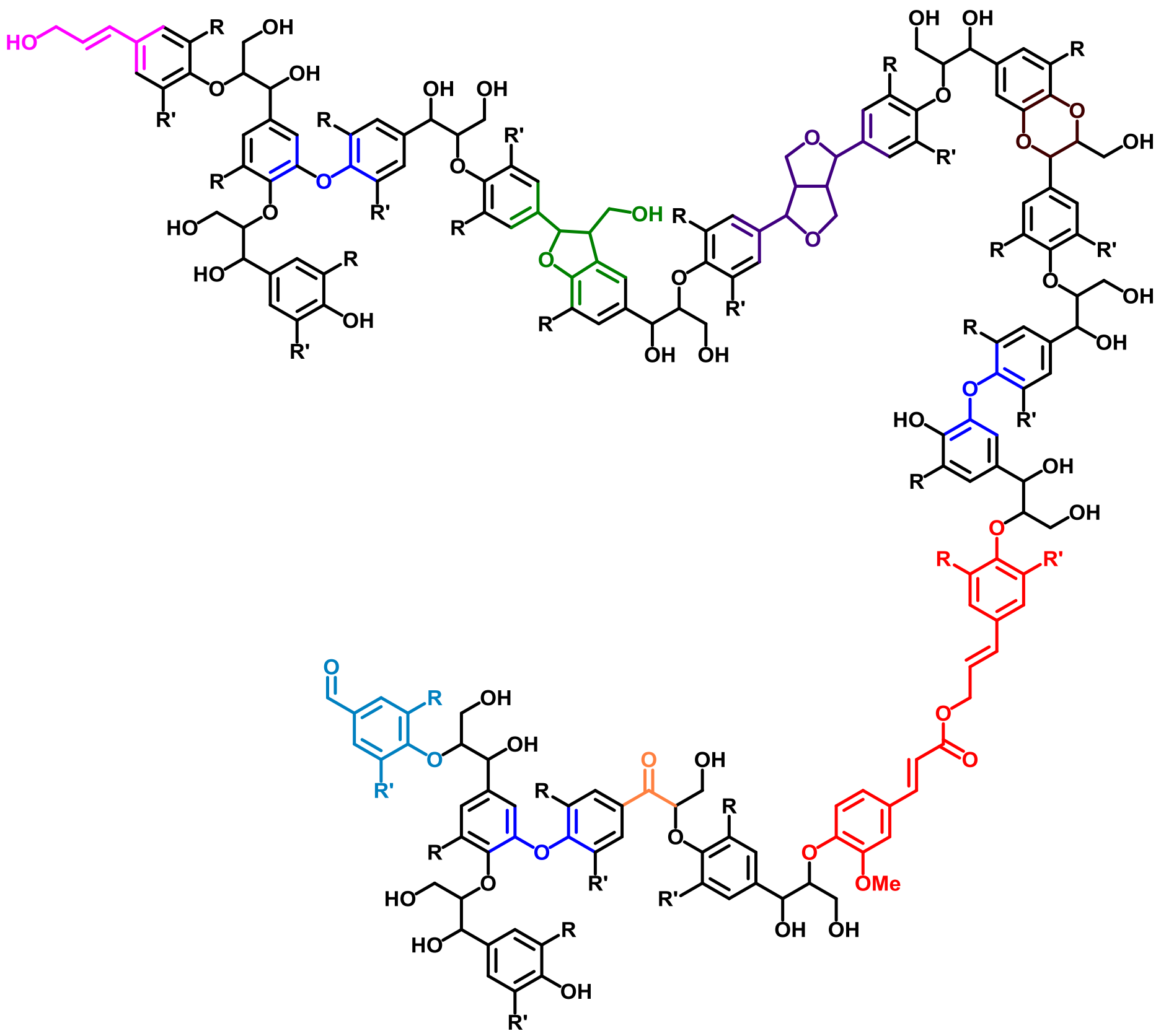

Figure 3. A model of lignin polymer illustrates the native and modified monomers and structural units. The major monomers are coniferyl alcohols $\left(R=O M e, R^{\prime}=H\right)$ and sinapyl alcohols $\left(R=R^{\prime}=O M e\right)$, and the major structural units are $\beta$-ether units (black) in wild-type plants. Wild-type lignin also includes phenylcoumaran units (green), resinol units (purple), and biphenyl ether units (blue). Cinnamyl alcohols $\left(R=O M e, R^{\prime}=O M e\right.$ or $\mathrm{H})$ (pink) and hydroxybenzaldehydes ( $\mathrm{R}=\mathrm{OMe}, \mathrm{R}^{\prime}=\mathrm{OMe}$ or $\mathrm{H}$ ) (cyan) are often seen as end groups. Incorporation of caffeyl alcohol $(\mathrm{R}=\mathrm{H})$ or 5-hydroxyconiferyl alcohol $(\mathrm{R}=\mathrm{OMe})$ results in benzodioxane units (brown) in the lignin polymers. Incorporation of monolignol ferulate (red) introduces the ester bond into the lignin backbone, forming ZipLignin ${ }^{\mathrm{TM}}$. Oxidation of hydroxyl group on the $\alpha$-carbon results in $\alpha$-keto $\beta-\mathrm{O}-4$ linkages (orange). 


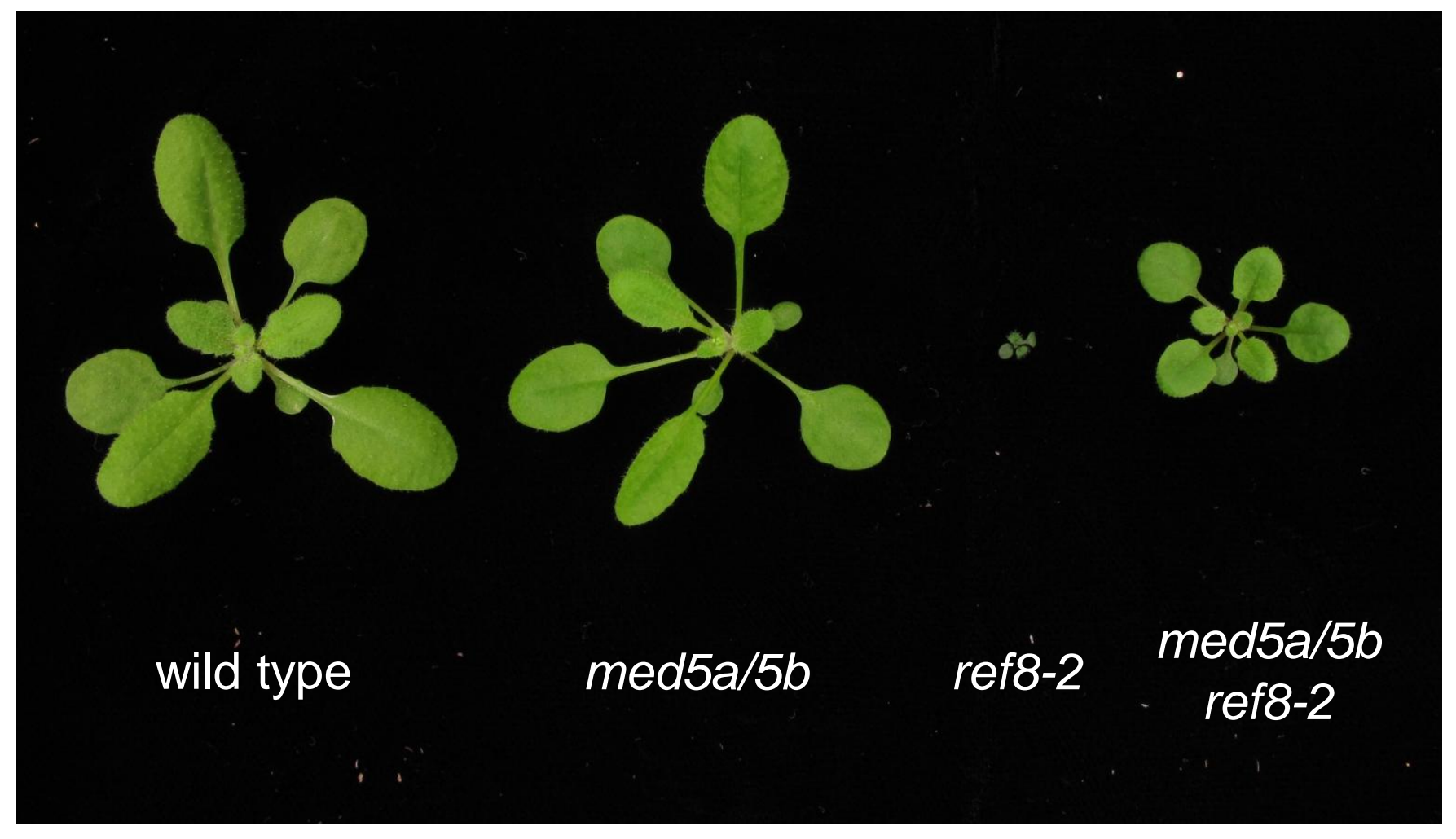

Figure 4. Knocking-out MED5a and MED5b substantially rescues the arrested growth of Arabidopsis ref8-2 mutant that contains a T-DNA insertion in the gene encoding $\mathrm{C}^{\prime} \mathrm{H}$. Wild-type, med5a/5b, ref82 , and med5a/5b ref8-2 plants were photographed four weeks after planting. The ref8- 2 mutant is dwarf and sterile, but the triple mutant med5a/5b ref8-2 has restored growth and is fertile. Photograph provided by Nicholas D. Bonawitz. 
Graphical Abstract (for review)

lignocellulose with

native lignin
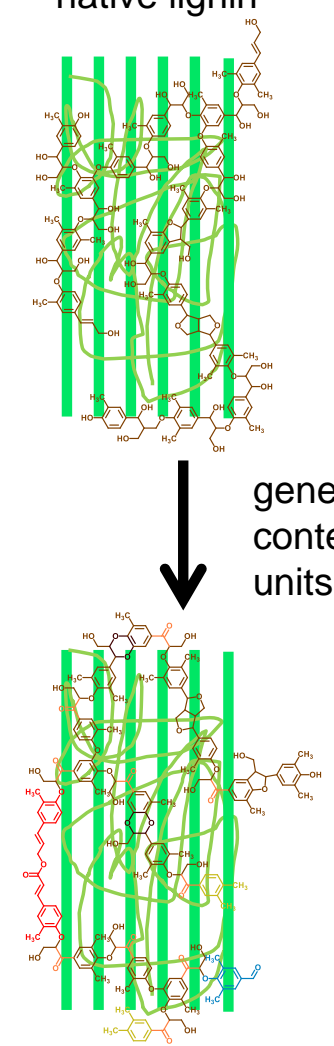

modified lignin

modified lignin
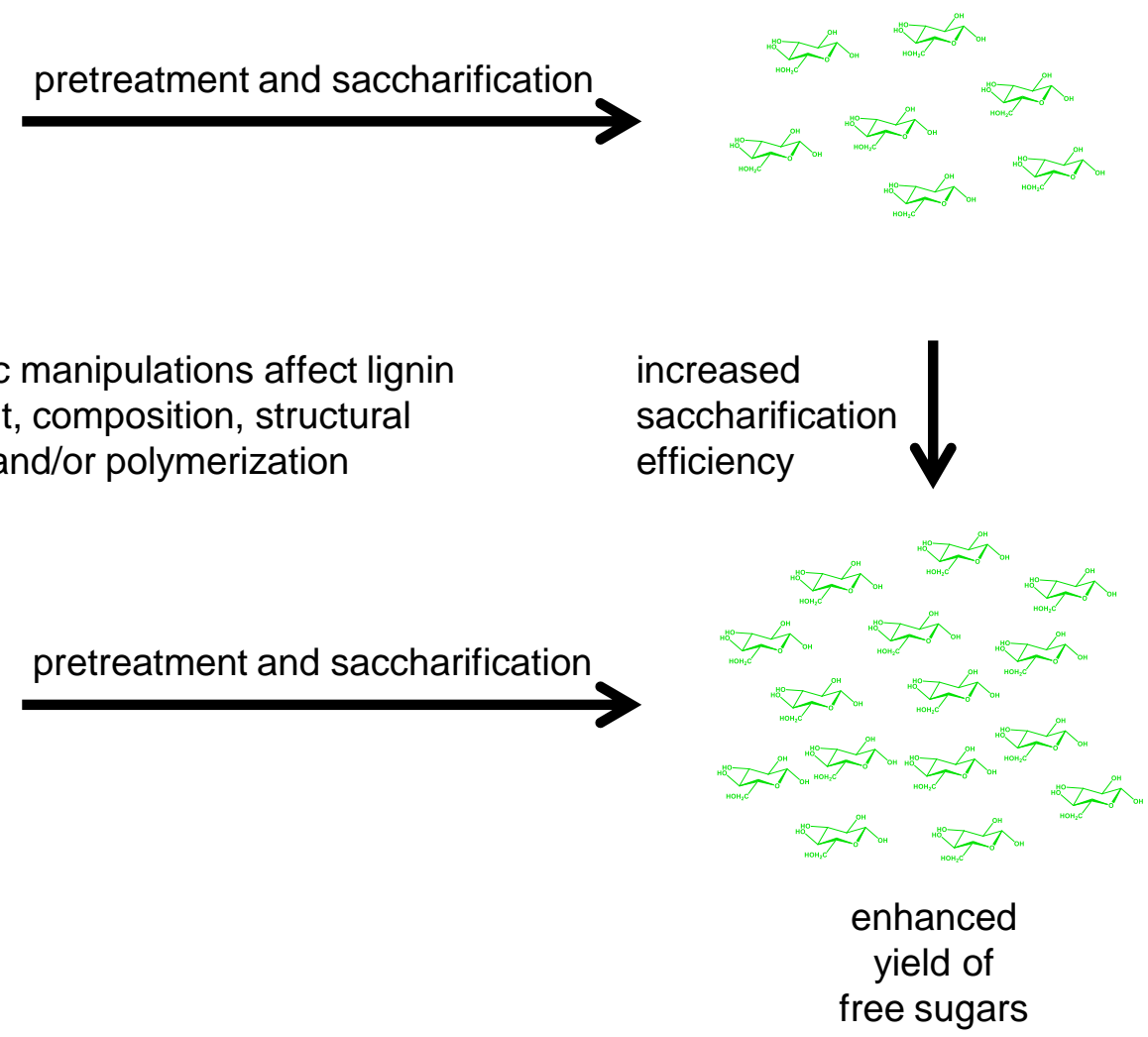

yield of pretreatment and saccharification

manipulations affect lignin ontent, composition, structural
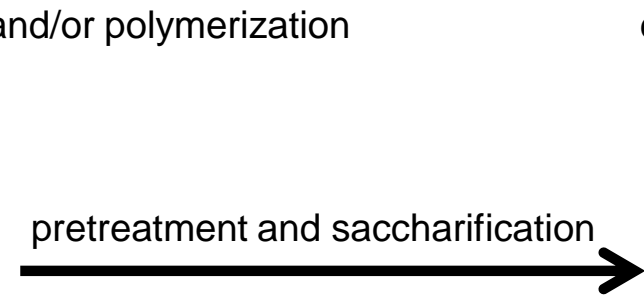

free sugars 